\title{
Life Cycle Cost Analysis (LCCA) in Road Organization Application in Supiori Regency of Papua Province
}

\author{
Fitriah Menufandu $^{1}$, Ary Setyawan ${ }^{2}$, Budi Yulianto ${ }^{2}$ \\ ${ }^{l}$ Student of Civil Engineering Faculty Master Program University eleven Maret Surakarta \\ ${ }^{2}$ Lecturer of Civil Engeneering Facuty University Eleven Maret Surakarta \\ *Corresponding author: fitriah_menufandu@yahoo.com
}

\begin{abstract}
Road plays an important life in human life in the present and in the future. Road serves to connect one area to another. Good road condition can support land transportation, development, economy, and government can run smoothly, and vice versa. Many factors result in road damage so that service life of road is not as planned. The objective of research is to compare two roads: Aminweri-Yendoker Street constituting the road in Supiori Regency Biak-Korem-Supiori Street constituting the national road connecting Biak and Supiori Regencies. This research employed Pavement Condition Index (PCI) to assess road damage level and condition and Life Cycle Cost Analysis (LCCA) to determine the economic cost during the road's service life. The result of assessment using PCI method showed medium PCI score of 51.6 for Regency road and 69.3 for National road. Using LCCA method, the most efficient road management to achieve the service life of the two roads can be determined.
\end{abstract}

Keywords-Road, Management, PCI, LCCA.

\section{INTRODUCTION}

$\mathrm{R}$ oad infrastructure plays an important role to human life in the present and the future. The existing road should be maintained well to maintain its performance according to its service life.

The existing road damage is often due to both natural and human factors. The mild damage condition needs maintenance to prevent the more severe damage requiring expensive cost from occurring.

The assessment on road damage can be done using some methods, one of which is Pavement Condition Index (PCI). PCI can be conducted directly on road damage using simple tools but with more accurate data and type of damage.

Real Cost 2.5 is a program used to estimate Life Cycle Cost Analysis (LCCA). LCCA is intended to determine the economic cost of highway rehabilitation, maintenance, and construction planning.

PCI will be used to determine road damage level and condition, while LCCA to determine the economic cost of road. These two methods are used to compare Aminweri-Yendoker Street constituting Regency road in Supiori and Biak-Korem-Supiori Street constituting National road connecting Biak and Supiori Regencies. This research aims: 1) to find out the damage level and road hardening condition in Aminweri-Yendoker Street and Biak-Korem-Supiori Street using PCI assessment, and 2) to find more economic cost for Aminweri-Yendoker Street and Biak-Korem-Supiori Street using LCCA method.

\section{METHOD}

\subsection{Research Location}

The location of this research is Aminweri-Yendoker road which is Supiori District and Biak-KoremSupiori road which is the national road connecting Biak Regency and Supiori Regency. Map of Aminweri-Yendoker road and road network and BiakKorem-Supiori road can be seen in Figure 2.1 and Figure 2.2.

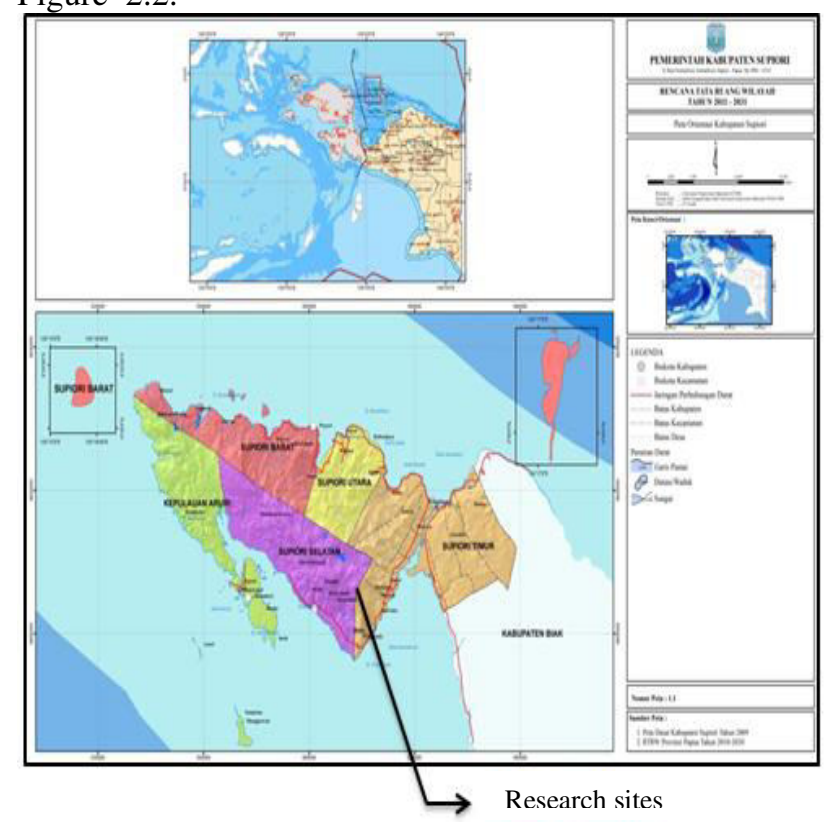

Figure 2.1. Aminweri-Yendoker road map and location map 


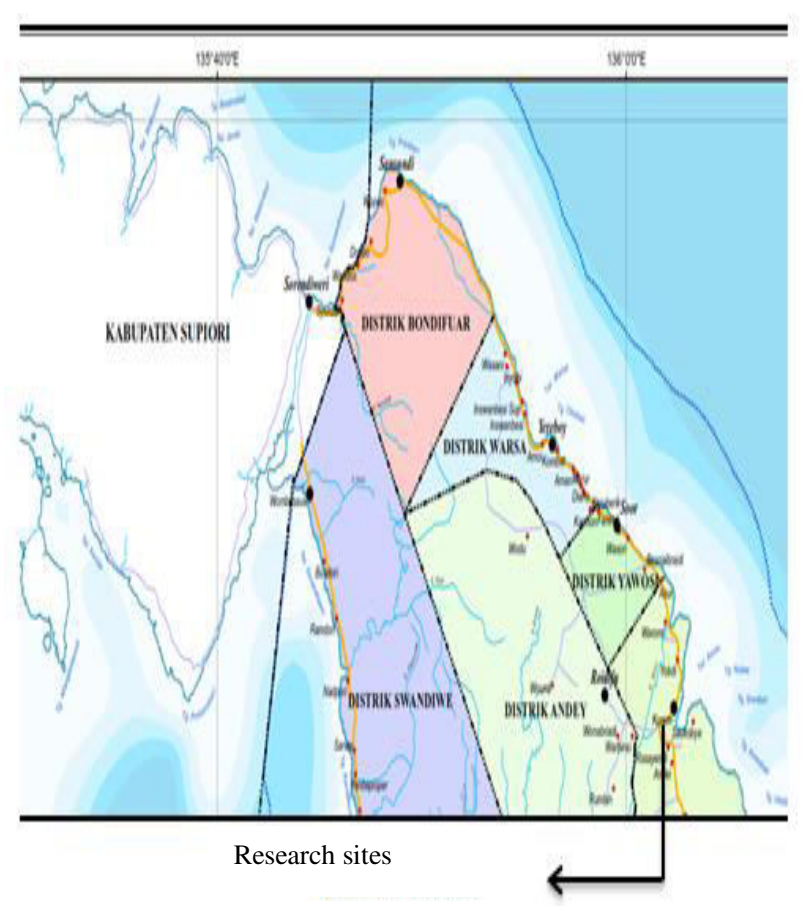

Figure 2.2. Biak-Korem-Supiori road map and location map

\subsection{Method and analysis}

1. Determine value density or levels damage Density or concentration of the damage is extensive or the percentage of the total length of the types of damage to the area or length measured total road section, can be in sq. $\mathrm{ft}$ or $\mathrm{m}^{2}$. Thus can be expressed by the following equation:

Desity $=\frac{A_{d}}{A_{s}} \times 100 \%$

Or

$$
\text { Density }=\frac{L_{d}}{A_{\Omega}} \times 100 \%
$$

2. Value Reduction (deduct Value. DV)

Reduction value (deduct value) is a value for each type of damage that obtained from the curve of the relationship between the density (density) and deduct Value (value reduction).

3. Value Reduction Total (Total deduct Value. TDV)

Total reduction value (Total deduct Value. TDV) is the sum total of the value of the reduction (deduct value) for each sample.

4. Corrected Reduction Values (Corrected deduct Value. CDV)

CDV curve obtained from the relationship between the value of TDV with CDV value with the selection curve curved according to the number of individual values deduct the value that has a value greater than 2 .
If the CDV value is known, then the values for each unit can be known by Eq.

$$
\begin{aligned}
& \mathrm{PCI}_{(\mathrm{s})}=100-\mathrm{CDV} \\
& \mathrm{PCI}=\frac{2 \mathrm{PCI}_{(\mathrm{s})}}{\mathrm{N}}
\end{aligned}
$$

2.3. Parameters and variables research

\begin{tabular}{|c|c|}
\hline $\begin{array}{c}\text { Variable Condition } \\
\text { Values }\end{array}$ & Analysis \\
\hline Size of Damage & Density \\
\hline Density & Deduct Value (DV) \\
\hline Level damage & Deduct Value (DV) \\
\hline Deduct Value (DV) & $\begin{array}{l}\text { Total Deduct } \\
\text { Value (TDV) }\end{array}$ \\
\hline $\begin{array}{l}\text { Total Deduct Value } \\
\text { (TDV) }\end{array}$ & $\begin{array}{l}\text { Correted Deduct Value } \\
\text { (CDV) }\end{array}$ \\
\hline $\begin{array}{l}\text { Corrected Deduct } \\
\text { Value (CDV) }\end{array}$ & $\begin{array}{l}\text { PCI for each unit (PCI(s)) } \\
\text { Total PCI }\end{array}$ \\
\hline \multicolumn{2}{|l|}{ Number of units $(\mathrm{N})$} \\
\hline & Total PCI \\
\hline $\begin{array}{l}\text { PCI value for each unit } \\
(\mathrm{PCI}(\mathrm{s}))\end{array}$ & Scoring scale \\
\hline Total PCI value & Pavement condition \\
\hline Scoring scale & \\
\hline
\end{tabular}

Parameters and variables used to describe

Table 2.1. Parameters and PCI Variables

Table 2.2 Parameters and Variable Handling

\begin{tabular}{clll}
\hline \multicolumn{1}{c}{ Parameter } & \multicolumn{1}{c}{ Variable } & Analysis & Value \\
\hline Pavement Conditions & $\begin{array}{l}\text { Do Nothing } \\
\text { (Corretive } \\
\text { Maintanance) }\end{array}$ & Excellen & $85-100$ \\
Pavement Conditions & $\begin{array}{l}\text { Preventive } \\
\text { Maintenance }\end{array}$ & Good & $75-85$ \\
Pavement Conditions & Resuface & Fair & $58-74$ \\
Pavement Conditions & Rehabilitation & Poor & $40-57$ \\
Pavement Conditions & Reconstruction & Falled & $0-39$ \\
\hline
\end{tabular}

Tabel 2.3 Parameters and Variables LCCA

\begin{tabular}{ll}
\hline \multicolumn{1}{c}{ Parameter } & \multicolumn{1}{c}{ Variable } \\
\hline $\begin{array}{l}\text { Eatabilish design strategy } \\
\text { alternatif }\end{array}$ & Project detail \\
& Analysis option \\
& Traffic data \\
& Value of user time \\
& Traffic hourly \\
& distribution \\
& Added vechicle time and \\
& cost
\end{tabular}




\begin{tabular}{ll}
$\begin{array}{l}\text { Determmine activity } \\
\text { timing }\end{array}$ & Alternative scenario \\
$\begin{array}{l}\text { Estimate agency and user } \\
\text { cost }\end{array}$ & Alternative scenario \\
Compute life cycle costs & $\begin{array}{l}\text { Deterministic result } \\
\text { \&simulation }\end{array}$ \\
Analyze the result & Pbobabilitic result \\
\hline
\end{tabular}

\section{RESULT OF ANALYSIS AND DISCUSSION}

\subsection{Data collection and analysis}

Aminweri-Yendoker-Koridor Street is the Supiori Regency road connecting South Supiori to East Supiori Districts, in which East Supiori is the center of Supiori Regency government. Meanwhile, BiakKorem-Supiori Street is the national road connecting Biak to Supiori Regencies. Visual survey shows that the road hardening condition of Regency street has 6 $\mathrm{m}$ width and $2 \mathrm{~km}$ length, while that of National road has $7 \mathrm{~m}$ width and $2 \mathrm{~km}$ length. For accurate measurement and analysis, each of streets is subdivided into 20 segments.

Data types of damage can be seen in figure 3.1a, figure $3.1 \mathrm{~b}$, figure $3.1 \mathrm{c}$, figure $3.2 \mathrm{a}$, figure $3.2 \mathrm{~b}$ and figure $3.2 \mathrm{c}$.

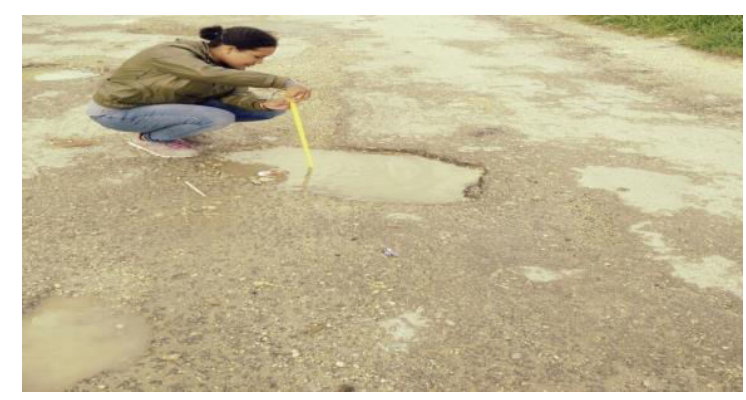

Figure 3.1a. Type of hole damage with high damage level on Aminweri-Yendoker road

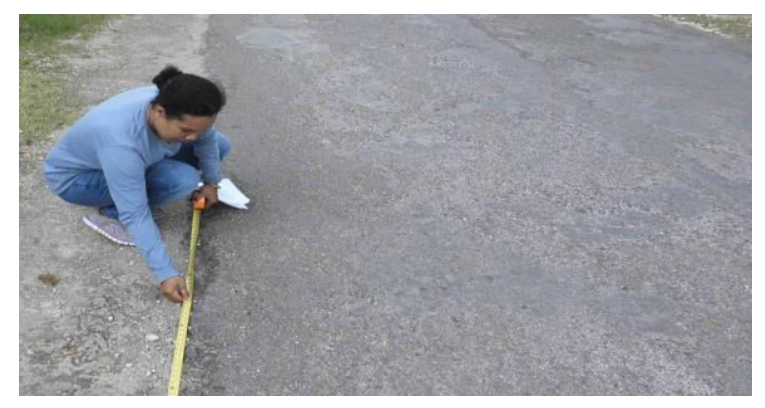

Figure 3.1b. Type of crack fracture edge with moderate damage level on Aminweri-Yendoker road

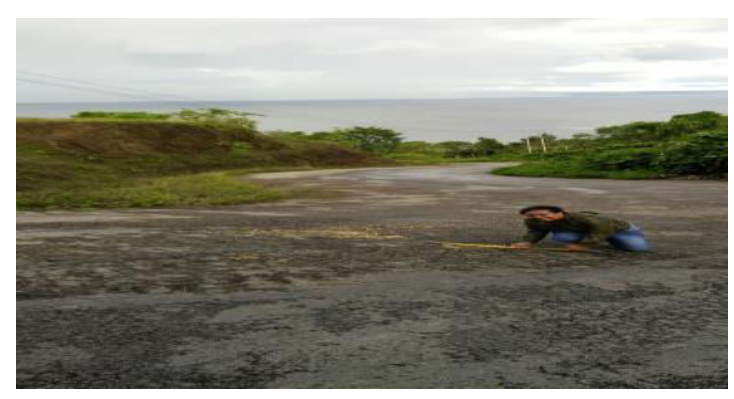

Figure 3.1c. Type weathering damage and raveling With high damage levels on the Aminweri-Yendoker road

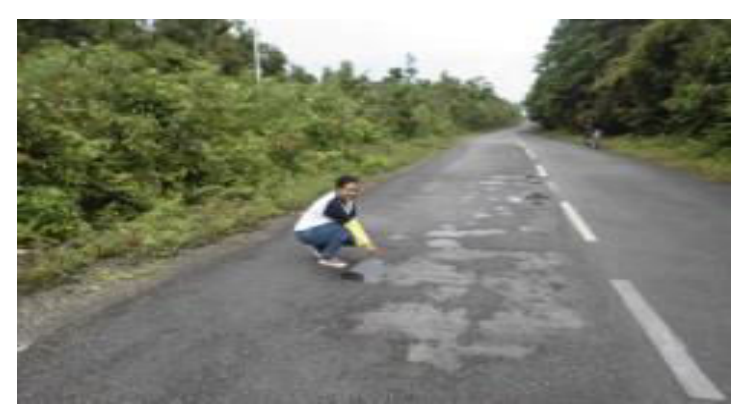

Figure 3.2a. Damage type Hole with high damage level on Biak-Korem-Supiori road

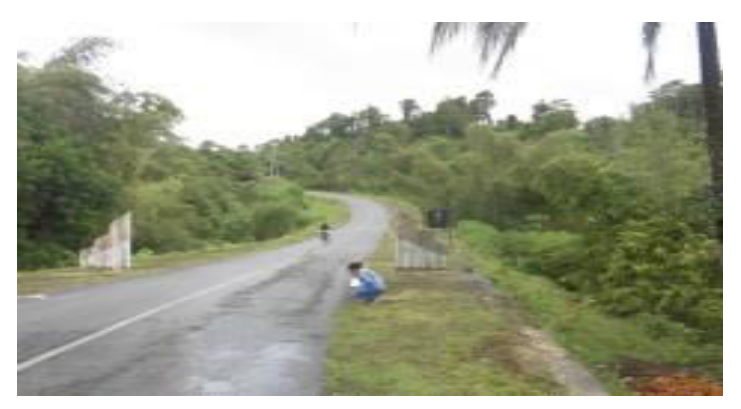

Figure 3.2b. Type of crack fracture edge with moderate damage level on Biak-Korem-Supiori road

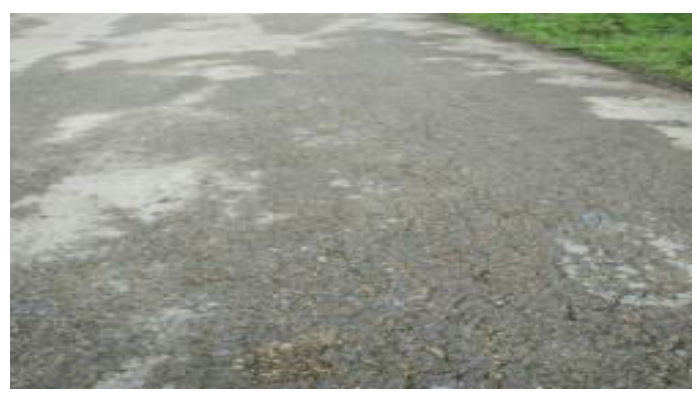

Figure 3.2c. Type weathering damage and raveling With a high degree of damage to the Biak-Korem-Supiori road

\subsection{PCI (Pavement Condition Index) Method}

1. Considering the data analysis conducted on the Biak-Korem Supiori Street divided into 20 segments, the result of visual survey is then estimated to find PCI value of individual segments. 
The result of PCI calculation can be seen in Table 3.1 and graph 3.1 below.

Table 3.1 Result of PCI analysis and road condition on 20 road segments in Biak-Korem-Supiori road segment

\begin{tabular}{cccc}
\hline NO & STA & PCI & CONDITION \\
\hline 1 & STA.37+800 - 37+900 & 76 & Satisfactory \\
2 & STA.37+900 - 38+000 & 74 & Satisfactory \\
3 & STA.38+000 - 38+100 & 78 & Satisfactory \\
4 & STA.38+100 - 38+200 & 77 & Satisfactory \\
5 & STA.38+200 - 38+300 & 82 & Satisfactory \\
6 & STA.38+300 - 38+400 & 80 & Satisfactory \\
7 & STA.38+400 - 38+500 & 80 & Satisfactory \\
8 & STA.38+500 - 38+600 & 76 & Satisfactory \\
9 & STA.38+600 - 38+700 & 76 & Satisfactory \\
10 & STA.38+700 - 38+800 & 76 & Satisfactory \\
11 & STA.38+800 - 38+900 & 57 & Fair \\
12 & STA.38+900 - 39+000 & 64 & Fair \\
13 & STA.39+000 - 39+100 & 65 & Fair \\
14 & STA.39+100 - 39+200 & 57 & Fair \\
15 & STA.39+200 - 39+300 & 59 & Fair \\
16 & STA.39+300 - 39+400 & 74 & Satisfactory \\
17 & STA.39+400 - 39+500 & 56 & Fair \\
18 & STA.39+500 - 39+600 & 66 & Fair \\
19 & STA.39+600 - 39+700 & 56 & Fair \\
20 & STA.39+700 - 39+800 & 56 & Fair \\
& flexural condition & $\mathbf{6 9 . 3}$ & Fair \\
\hline & & & \\
\hline
\end{tabular}

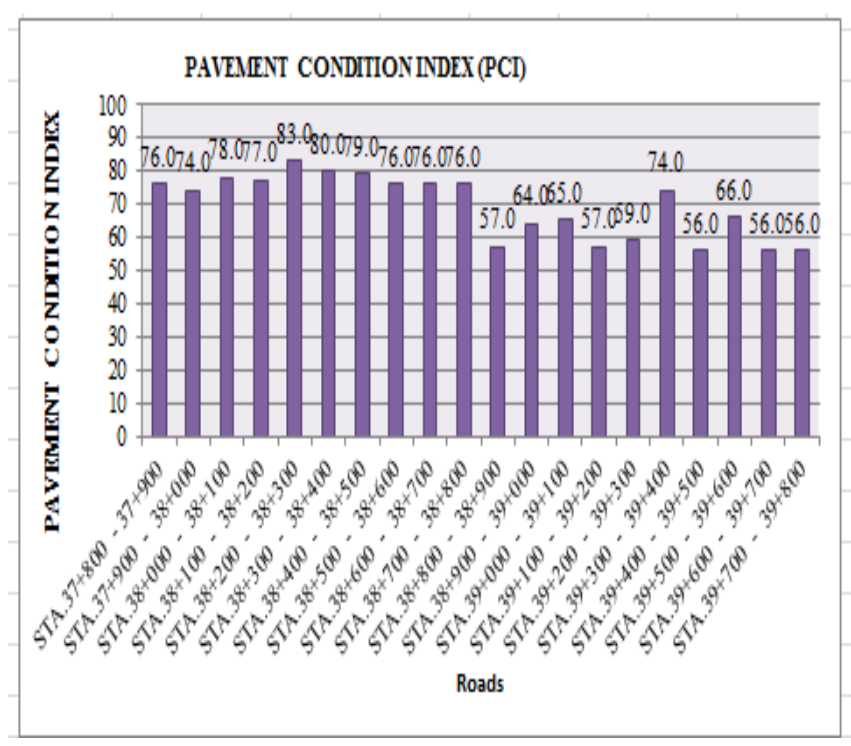

Graph 3.1. PCI Analysis and road conditions on 20 road segments on Biak-Korem-Supiori road
From Table 3.1 and graf 3.1, it can be found that the result of estimation from segment one (1) to (20) shows that the road condition is good thereby only requiring maintenance to prevent the further damage requiring more expensive cost from occurring.

2. Considering the data analysis conducted on the Aminweri-Yendoker Street divided into 20 segments, the result of visual survey is then estimated to find PCI value of individual segments. The result of PCI calculation can be seen in Table 3.2 and graph 3.2 below

Table 3.2 Result of PCI analysis and road condition on 20 road segments in Aminweri-Yendoker road segment

\begin{tabular}{cccc}
\hline NO & STA & PCI & CONDITION \\
\hline 1 & STA.0+000 - 0+100 & 50 & Poor \\
2 & STA.0+100 - 0+200 & 52 & Poor \\
3 & STA.0+200 - 0+300 & 54 & Poor \\
4 & STA.0+300 - 0+400 & 50 & Poor \\
5 & STA.0+400 - 0+500 & 56 & Fair \\
6 & STA.0+500 - 0+600 & 45 & Poor \\
7 & STA.0+600 - 0+700 & 48 & Poor \\
8 & STA.0+700 - 0+800 & 62 & Fair \\
9 & STA.0+800 - 0+900 & 54 & Poor \\
10 & STA.0+900 - 1+000 & 44 & Poor \\
11 & STA.1+000 - 1+100 & 45 & Poor \\
12 & STA.1+100 - 1+200 & 51 & Poor \\
13 & STA.1+200 - 1+300 & 51 & Poor \\
14 & STA.1+300 - 1+400 & 55 & Poor \\
15 & STA.1+400 - 1+500 & 64 & Fair \\
16 & STA.1+500 - 1+600 & 46 & Poor \\
17 & STA.1+600 - 1+700 & 54 & Poor \\
18 & STA.1+700 - 1+800 & 56 & Fair \\
19 & STA.1+800 - 1+900 & 50 & Poor \\
20 & STA.1+900 - 2+000 & 47 & Poor \\
& Average pavement & $\mathbf{5 1 . 6}$ & Poor \\
\hline & flexural condition & \\
\hline
\end{tabular}




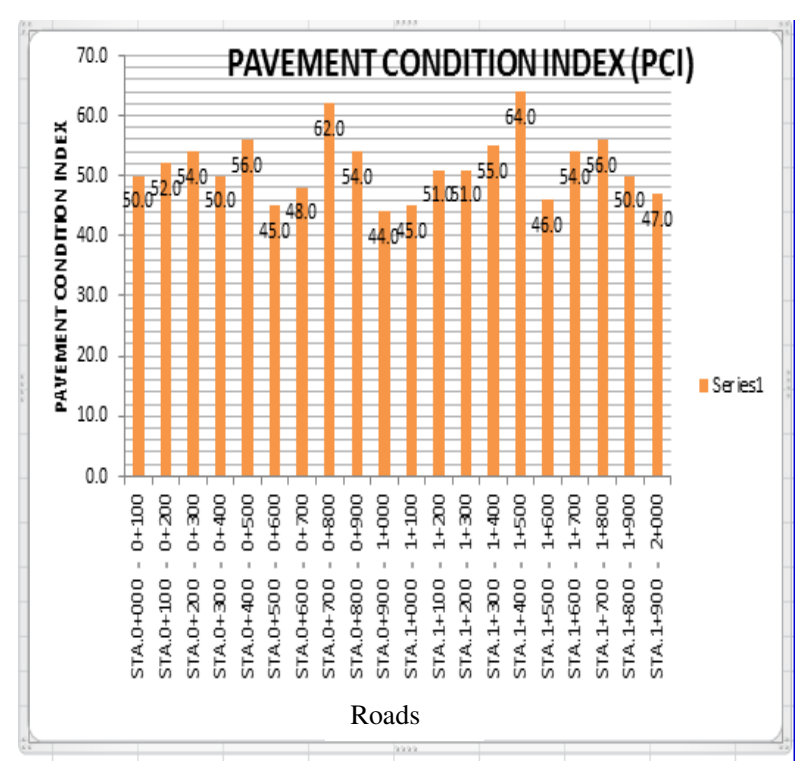

Graph 3.2. PCI Analysis and road conditions on 20 road segments on Aminweri-Yendoker road

From Table 3.2 and graph 3.2, it can be found that the result of estimation from segment one (1) to (20) shows that the road condition is poor (medium) thereby requiring rehabilitation so that it encounters worse damage and requires expensive cost.

The damage level of Aminweri-Yendoker Street is: $51.6 \%$ and that of Biak-Korem-Supiori Street is $69.3 \%$.

\section{Table 3.3. Damage Condition}

From the damage level obtained, the severity level of Aminweri-Yendoker Street is on "medium" (poor) condition, while that of Biak-Korem-Supiori Street is on "good" condition, as illustrated in

\begin{tabular}{lllllll}
\multicolumn{7}{c}{ Table 3.3. Damage condition } \\
\hline Good & Satisfactory & Fair & Poor & Very & Serious & Failed \\
100 & 85 & 70 & 55 & 49 & 25 & 10 \\
\hline
\end{tabular}

\subsection{Determine Type Handling}

Considering the PCI value obtained in Biak-KoremSupiori Street, the management type used is "Maintenance", as illustrated in figure 3.4. Meanwhile, for Aminweri-Yendoker Street, the management type used is "Rehabilitation", as illustrated in figure 3.3. The handling will be done on the Aminweri-Yendoker road and Biak-KoremSupiori road segment based on the results of data on road damage and data analysis based on PCI method, the result obtained for Aminweri-Yendoker road with PCI value is 51.6. The condition of the road at PCI motede of numbers 41-55 belong to the state of "Medium (Poor)" can be seen in Figure 3.4, so it needs to be rehabilitated. Rehabilitation shall be carried out for the prevention of widespread damage and any damage not to be taken into account in the design, resulting in a decrease in the condition of stability in a particular part or place of the lane of the road with a minor damage condition, in order to decrease the condition of steadiness it can be returned in a condition of mood according to the plan. The combination between PCI and Handling for Aminweri-Yendoker road can be seen in table 3.4. While the results obtained for Biak-Korem-Supiori road with a PCI value of 69.3 . The condition of the road at PCI motede of numbers 56-70 belong to the state of "Biak (Fair)" can be seen in figure 3.3, so that the necessary maintenance. Maintenance is carried out for road handling, in the form of prevention, maintenance, and repair needed to maintain road condition in order to keep functioning optimally to serve the traffic so that the design life can be achieved. The combination between PCI and Handling for BiakKorem-Supiori roads can be seen in Table 3.4.

Tabel. 3.4 Pavement Condition Index

\begin{tabular}{lllllll}
\hline Good & Satisfactory & Fair & Poor & $\begin{array}{l}\text { Very } \\
\text { Poor }\end{array}$ & Serious & Failed \\
100 & 85 & 70 & 55 & 49 & 25 & 10 \\
\hline
\end{tabular}

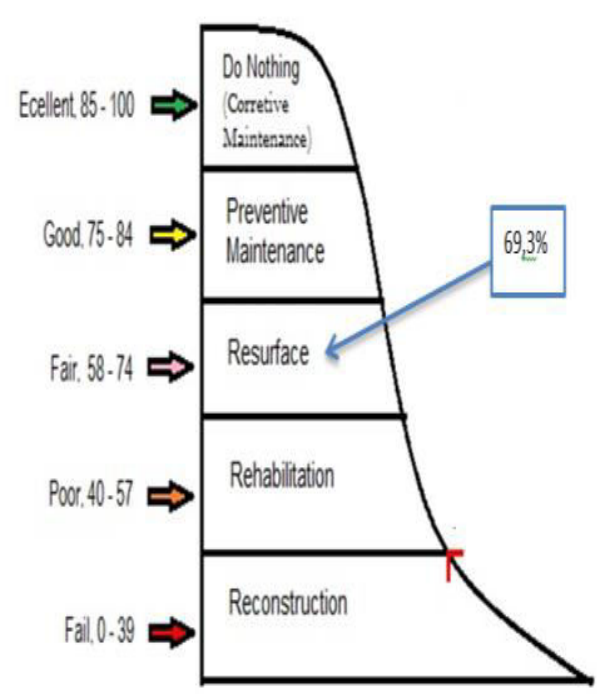

Figure 3.3. Determining Management Type for BiakKorem-Superiori Street 


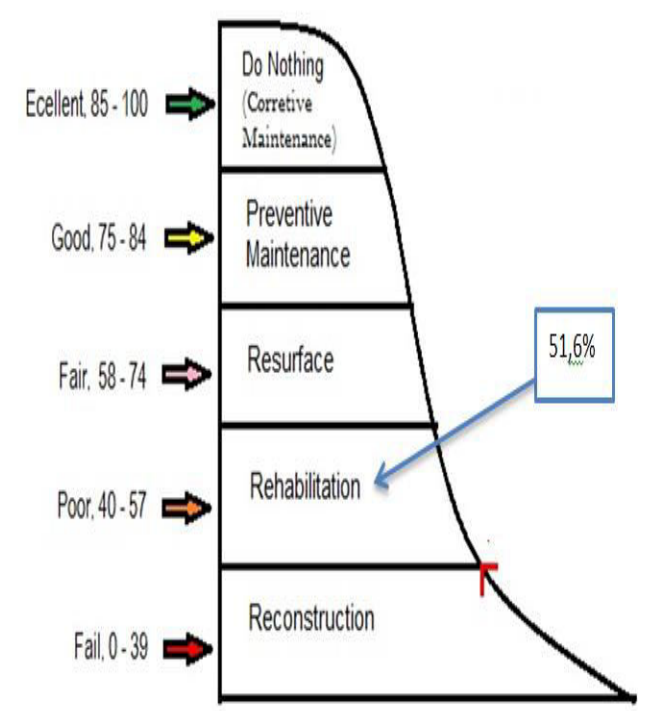

Figure 3.4. Determining management type for Aminweri-Yendoker Street

\subsubsection{Rehabilitation}

Rehabilitation was performed based on PCI analysis of damage obtained in the field. So for the road Aminweri-Yendoker only done rehabilitation on the thick layer of thin asphalt sand (latasir) and macadam penetration layer (lapen). The pavement thickness data obtained from Supiori District Public Works Office on the road planning in 2013 with $3 \mathrm{~cm}$ thick latasir and $7 \mathrm{~cm}$ thick thickness will be rehabilitated in two stages: the first 10 rehabilitation is done once with a thickness of $10 \mathrm{~cm}$, and 10 second year rehabilitation is done once with a thickness of 10 $\mathrm{Cm}$ for the 20-year plan age so that road conditions continue to function optimally. Result of recapitulation of rehabilitation of Aminweri-Yendoker road can be seen in table $3.5 \mathrm{a}$ and table $3.5 \mathrm{~b}$.

Table. 3.5a. Recapitulation of rehabilitation result of first

\begin{tabular}{|c|c|c|}
\hline & Aitem pavement phase I (10 years) & $\begin{array}{l}\text { Thickness of } \\
\text { pavement }\end{array}$ \\
\hline- & Thick thin layer of sand asphalt (Latasir) & $3 \mathrm{~cm}$ \\
\hline 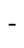 & Macadam penetration layer (Lapen) & $7 \mathrm{~cm}$ \\
\hline
\end{tabular}

Table. 3.5b. Recapitulation of 10 years rehabilitation result of both road segments Aminweri-Yendoker

\begin{tabular}{lll}
\hline & Aitem pavement phase I (10 years) & $\begin{array}{l}\text { Thickness of } \\
\text { pavement }\end{array}$ \\
- & Thick thin layer of sand asphalt (Latasir) & $3 \mathrm{~cm}$ \\
- $\quad$ Macadam penetration layer (Lapen) & $7 \mathrm{~cm}$ \\
\hline
\end{tabular}

\subsubsection{Maintenance}

Maintenance is done based on PCI analysis results from damage obtained in the field. So for the road Biak-Korem-Supiori maintenance is only done on the thick layer of thin asphalt sand (latasir). The pavement thickness data obtained from Working unit on road planning in 2013 with $4 \mathrm{~cm}$ thick latasir it will be done in maintenance of two stages of the first 10 carried out one-time maintenance with a thickness of $4 \mathrm{~cm}$, and the second 10 years of maintenance is done once with a thickness of $4 \mathrm{~cm}$ for the age of 20 years so the road Keep functioning optimally. Result of recapitulation of road maintenance Aminweri-Yendoker can be seen in table 3.6a and table 3.6b.

Table 3.6a. Recapitulation of the first 10 years of BiakKorem-Supiori maintenance

\begin{tabular}{cl}
\hline Aitem pavement phase I (10 years) & $\begin{array}{l}\text { Thickness of } \\
\text { pavement }\end{array}$ \\
- & $4 \mathrm{~cm}$ \\
\hline
\end{tabular}

Table 3.6b. Recapitulation of the second Biak-KoremSupiori 10-year maintenance result

\begin{tabular}{ll}
\hline Aitem pavement phase I (10 years) & $\begin{array}{l}\text { Thickness of } \\
\text { pavement }\end{array}$ \\
- & $4 \mathrm{~cm}$ \\
\hline
\end{tabular}

\subsection{RAB Estimation}

3.4.1. Estimation (RAB) thick thin layer of asphalt sand (Latasir) and layer penetration macadam (Lapen) segment Street Aminweri-Yendoker

Estimation (RAB) for rehabilitation of sandpaper asphalt layer (latasir) and macadam penetration layer (lapen) on Aminweri-Yendoker road in the first 10 years and 10 second year based on total area of road damage obtained from PCI.

Pavement road pavement there are two scenarios, the first scenario and the second scenario being done in each stage, phase I (10) years and phase II (10) years, as in Table 3. 7 .

Table 3.7. Scenario I $(10+10)$ years of Aminweri-Yendoker road section

\begin{tabular}{lcc}
\hline $\begin{array}{l}\text { Value of the } \\
\text { project }\end{array}$ & Rp & $\$$ \\
Tahp I & $1.200 .520 .000,00$ & $90.169,74$ \\
Tahap II & $1.503 .490 .000,00$ & $112.925,49$ \\
\hline
\end{tabular}

3.4.2. Estimation (RAB) thick thin layer of asphalt sand (latasir) Biak-Korem-Supiori

The budget plan (RAB) for the maintenance of the thickness of the sandblast (latasir) layer on the BiakKorem-Supiori road in the first 10 years and the second 10 years based on the total area of road damage obtained from PCI pavement roads there are two scenarios namely the first scenario And the 
second scenario worked on each phase, phase I (10) years and phase II (10) years, as in Table 3.8 .

Table 3.8. Scenario II $(10+10)$ years of Biak-KoremSupiori road segment

\begin{tabular}{lcc}
\multicolumn{3}{c}{ Supiori road segment } \\
\hline $\begin{array}{c}\text { Value of the } \\
\text { project }\end{array}$ & Rp & $\$$ \\
Tahp I & $575.380 .000,00$ & $43.216,16$ \\
Tahap II & $926.720 .000,00$ & $69.604,92$ \\
\hline $1 \$=13.314$ &
\end{tabular}

a. LCCA estimation using RealCost 2.5 Software

RealCost 2.5 is the program used to estimate Life Cycle Cost Analysis (LCCA). LCCA is intended to estimate economic cost in road construction work including maintenance, rehabilitation, and planning. In LCCA, there are two alternative and two activities used to estimate the economic project expense cost and operational economist cost of vehicle during the road's service life. RealCost Software 2.5.

The procedure in RealCost 2.5 Software includes:

1. Project Level Input

2. Alternative Level Input

3. Input Warning

4. Simulation and Outputs

5. Administrative Function

Project Level Input consists of: Project Detail, Analysis Options, Traffic Data, Value of User Time, Traffic Hourly Distribution, Added Vehicle Time and Cost. Alternatives is the process of selecting scenarios and activities in the type of management worked on and construction, maintenance, and rehabilitation costs. Rehabilitation and Maintenance Scenarios can be seen in Table 3.12 with RAB of Rehabilitation in scenario I $(10+10)$ years and that in scenario II $(10+10)$ years. The data inputted into Alternative scenarios is then simulated. Deterministic Result value of input for Aminweri-Yendoker and Biak KoremSupiori Streets shows the economic cost result in alternative 2 of scenario II, as shown in table 3.9

Tabel 3.9 Deterministic Result

\begin{tabular}{lllll}
\hline & $\begin{array}{l}\text { Altenative 1 : District } \\
\text { road scenario I }\end{array}$ & $\begin{array}{l}\text { Altenative 2 : National } \\
\text { road Scenario II }\end{array}$ & Agency \\
Total Cost & $\begin{array}{l}\text { Agency Cost } \\
(\$ 1000)\end{array}$ & $\begin{array}{l}\text { Agency } \\
\text { Cost } \\
(\$ 1000)\end{array}$ & $\begin{array}{l}\text { Agency Cost } \\
(\$ 1000)\end{array}$ & $\begin{array}{l}\text { Cost } \\
(\$ 1000)\end{array}$ \\
$\begin{array}{l}\text { Undiscounted } \\
\text { Sum }\end{array}$ & $\$ 1.916 .409,25$ & $\$ 0.72$ & $\$ 1.611 .554,00$ & $\$ 0.36$ \\
$\begin{array}{l}\text { Present Value } \\
\text { EUAC }\end{array}$ & $\$ 1.502 .876,00$ & $\$ 0.50$ & $\$ 1.309 .837,25$ & $\$ 0.26$ \\
$\begin{array}{l}\text { Lowest } \\
\text { Present Value } \\
\text { Agency Cost }\end{array}$ & Alternative 2 national road scenario II & $\$ 0.02$ \\
$\begin{array}{l}\text { Lowest } \\
\text { Present Value } \\
\text { User Cost }\end{array}$ & Alternative 2 national road scenario II & \\
\hline
\end{tabular}

Expenditure Stream explains the funding for the working 20 years, in this part, software has determined repairing time and its cost, as shown in Table 3.13.

Table 3.10 Expenditure Stream

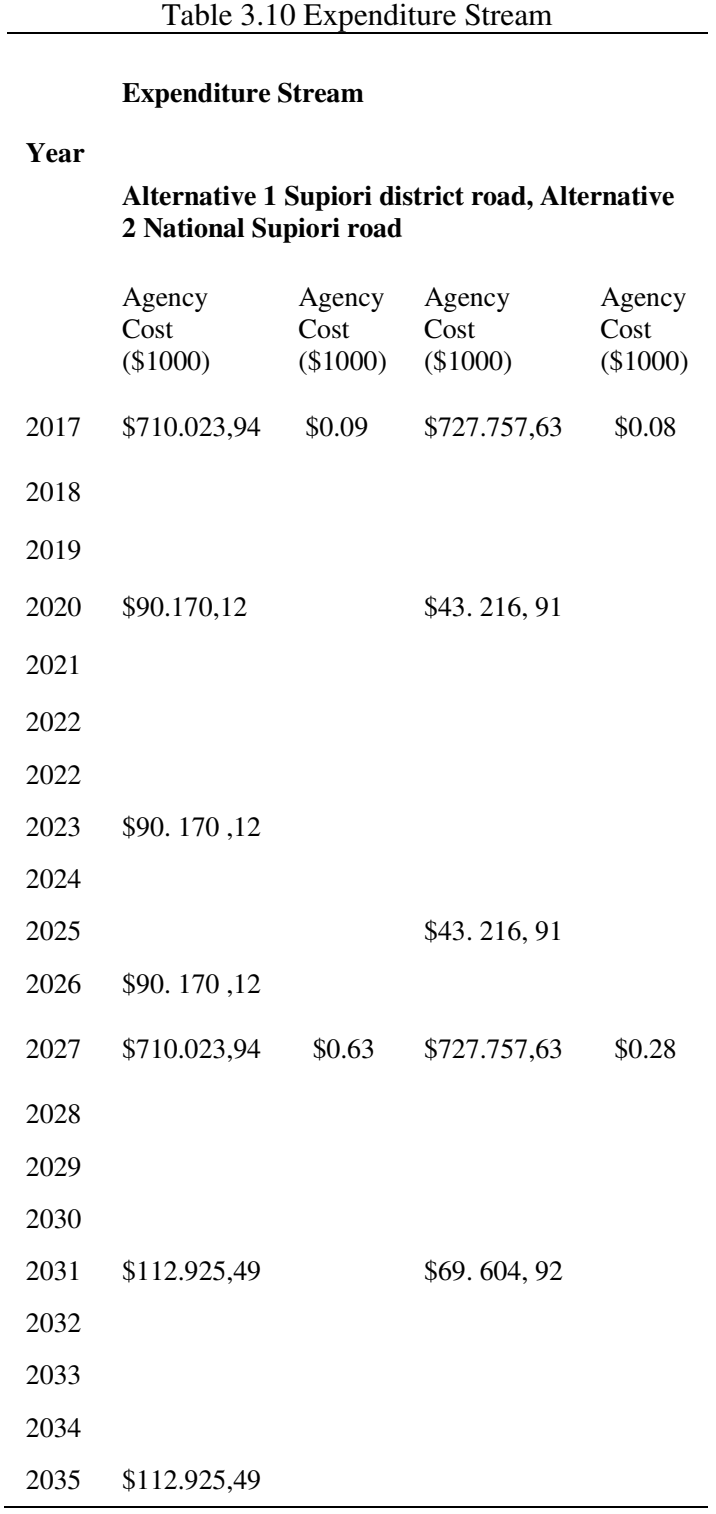

Simulation serves to produce Probabilistic Result. Probabilistic value of simulation result for AminweriYendoker and Biak-Korem-Supiori Streets shows that the minimum cost is on Alternative 2 scenario II, with the values presented in table 3.14. Probability scale for Aminweri-Yendoker and Biak-Korem-Supiori Street works shows Minimum Agency Cost of $0.23 \%$ on Alternative 2 scenario II. While the Maximum Cost Agency is $0.21 \%$ on Alternative 1 Scenario I. 
Tabel 3.14. Probabilistic result of Aminweri-Yendoker and Biak-Korem-Supiori Street works

\begin{tabular}{lllll} 
& \multicolumn{2}{l}{ Biak-Korem-Supiori Street works } \\
\hline $\begin{array}{l}\text { Total Cost } \\
\text { (Present Value) }\end{array}$ & $\begin{array}{l}\text { Alternative 1: Jalan } \\
\text { Kabupaten Skenario I } \\
\text { Agency Cost } \\
\mathbf{( \$ 1 0 0 0 )}\end{array}$ & $\begin{array}{l}\text { Agency } \\
\text { Cost } \\
\mathbf{( \$ 1 0 0 0 )}\end{array}$ & $\begin{array}{l}\text { Kabupaten Skenario II } \\
\text { Agency Cost } \\
\mathbf{( \$ 1 0 0 0 )}\end{array}$ & $\begin{array}{l}\text { Agency } \\
\text { Cost } \\
\mathbf{( \$ 1 0 0 0 )}\end{array}$ \\
$\begin{array}{l}\text { Mean } \\
\begin{array}{l}\text { Standard } \\
\text { Deviation }\end{array}\end{array}$ & $\$ 90.444,85$ & $\$ 0,05$ & $\$ 86.865,94$ & $\$ 0,02$ \\
Minimum & $\$ 1.234 .345,88$ & $\$ 0,37$ & $\$ 1.041 .641,25$ & $\$ 0,19$ \\
Maximum & $\$ 1.763 .533,00$ & $\$ 0,65$ & $\$ 1.558 .518,88$ & $\$ 0,34$ \\
\hline
\end{tabular}

\section{CONCLUSION AND RECOMMENDATION}

\subsection{Conclusion}

Considering the result of research conducted on Aminweri-Yendoker and Biak-Korem-Supiori Streets, the following conclusions can be drawn:

1. Pavement Severity Level of Aminweri-Yendoker Street has PCI value of $51.6 \%$ belonging to "medium (poor) condition, so that Rehabilitation should be done. That of Biak-Korem-Supiori Street has PCI value of $69.3 \%$ belonging to "good" condition, thereby requiring Maintenance.

2. From LCCA result, the LCCA value of Aminweri-Yendoker Street is on scenario I $(10+10)$ years "High Rehabilitation Cost", while LCCA value for Biak-Korem-Supiori Street is on scenario II $(10+10)$ years "Medium Maintenance Cost" so that it can be found the most economic project value for 20-year service life existing on scenario II.

\subsection{Recommendation}

To maintain the service life of Regency and National Roads in the future, the following points should be taken into account:

1. The assessment of PCI needs experience personnel in determining the type of road damage in the field.

2. LCCA method is very good to use as it provides economic cost in Maintenance, Rehabilitation and Planning for service life of road.

3. To maintain quality and economic cost of road structure in order to be consistent with the service life of road, gradual maintenance is required.

\section{REFERENCES}

[1] Ary Setyawan et al, Predicting the remaining service life of road using pavement condition index, Vol.125, pp. 1-7, 2015.

[2] Joao santos et al, LCCA System For Pavement Management: Sensitivity Analysis To The Discount rate,Vol. 53, pp. 1-10, 2010.

[3] Nur Izzi Md Yusoff et al, Evaluation of pavement life cycle cost analysis: Review and anslysis, Vol .9, pp.110, Agustus 2016.

[4] Jan Mikolaj et al, Life Cycle Analysis-Integral part of road network management system, Vol 91, pp. 1-6, 2014.

[5] State of California Departemen of Transportation Division of Maintenance Pavement Program, For RealCost Version 2.5CA, pp 33-85, Agustus 2013.

[6] Tingting Ding et al, Optimal Strategy Pavement Preventive Maintenance Considering Cycle Cost Analysis, Vol. 96, pp. 1-7, 2013.

[7] M.Y. Shahim, 1994, Pavements Management For airpots, Road, and Parking lots. Pp 345-501. 